\title{
Epidemiological trend of suicide in center of Iran from 2012 to 2016
}

\author{
Soheil Hassanipour ${ }^{\mathrm{a}, \mathrm{b}}$, Hamid Kazemi ${ }^{\mathrm{c}}$, Ali-Reza Ghayour ${ }^{\mathrm{c}}$, Amine Kazemi-Najafabadi ${ }^{\mathrm{d}}$, \\ Hossein-Ali Nikbakht ${ }^{\mathrm{b}, \mathrm{e}}$, Haleh Ghaem ${ }^{\mathrm{f}, *}$ \\ ${ }^{a}$ Gastrointestinal and Liver Diseases Research Center, Guilan University of Medical Sciences, Rasht, Iran \\ ${ }^{\mathrm{b}}$ Student Research Committee, Shiraz University of Medical Sciences, Shiraz, Iran \\ ${ }^{\mathrm{c}}$ Isfahan University of Medical Sciences, Isfahan, Iran \\ ${ }^{\mathrm{d}}$ University of Isfahan, Isfahan, Iran \\ ${ }^{\mathrm{e}}$ Social Determinants of Health Research Center, Health Research Institute, Babol University of Medical Sciences, Babol, Iran \\ ${ }^{\mathrm{f}}$ Research Center for Health Sciences, Institute of Health, Epidemiology Department, School of Health, Shiraz University of Medical Sciences, Shiraz, Iran
}

\section{A R T I C L E I N F O}

\section{Keywords:}

Suicide

Epidemiology

Trend

Iran

\begin{abstract}
A B S T R A C T
Objectives: Suicide is a conscious act in which the individual deliberately commit and unusual act with the intention of self-harm. The present study aims to examine some epidemiological factors affecting attempted and completed suicide rate during 2012-2016 in NajafAbad, a city in Isfahan province.

Methods: This is a cross-sectional study. The subjects are 2138 cases involved in suicide attempt during 2012-2016 that gone to Montazeri and Al-Zahra hospital. Chi-square, logistic regression and Cochran-Armitage test was used for data analysis.

Result: Totally, 1385 (64.8\%) patients were female and $47.8 \%$ were younger than 24 years of age. The most common method of suicide was medication overdose (91.1\%). In multivariable analysis, male gender (OR: 2.67; CI 95\% 1.53 to 4.64) was a risk factor for fatal suicide and application of chemical methods (OR: 0.018; CI 95\% 0.010 to 0.032 ) was a protective factor. Results regarding completed suicide trend analysis shows that this trend has had a significant statistical difference in men $(p=0.019)$ but in women this trend doesn't statistically significant difference. ( $p=0.209)$.

Conclusions: According to the findings of the present study, attempted and completed suicide rate in Najafabad is relatively high compared to other regions in Islamic Republic of Iran. The completed suicide rate was significant in men which achieved its greatest value in 2015. Suicide attempt rate didn't show a significant statistical difference in both men and women.
\end{abstract}

\section{Introduction}

Suicide is a conscious act in which the individual deliberately commit and unusual act with the intention of self-harm. ${ }^{1}$ Suicide is the 17 th cause of death in the world, the 3rd cause of death in the age group 15-24 years and also the 2nd in the age group 15-19 years. $^{2}$ During the last decade, evidence of rising suicide rates has turned to be the main concern of worldwide public health. In the world annually there are more than one million suicide attempts. ${ }^{3}$

During the last half a century, suicide attempt rate has shown an increasing trend so that it is estimated in 2020, about 1.530 .000 suicide attempts will occur in the world. ${ }^{3,4}$ Studies conducted in Iran have revealed different results. In a systematic and meta-analysis retrospective study, the completed and attempted suicide rate were examined in terms of 7 th climates of Iran. ${ }^{5}$ In this regard the articles published during the years 2001-2014 were included in the study. The highest rate of completed suicide in Islamic Republic of Iran is 12.9 per 100000 which is related to climate zone No.1, including Ilam, Lorestan, Hamedan, Kurdestan and Kermanshah. The lowest rate is 2.8 per 100000 related to climate zone No.5 including Isfahan, Yazd, Semnan and Qom. ${ }^{5}$ Another meta-analysis study revealed that suicide attempt trend in Iran is rising which is most common among women and age groups $15-24$ years. $^{6}$

Demographic factor such as gender has separate effects on suicidal behaviors. Results from other studies show that the proportion of serious suicide attempts among all non-fatal suicidal acts with known was significantly higher in men than in women. ${ }^{7,8}$ A lower rate of attempted and a higher rate of completed suicides result in major gender differences in the lethality of suicidal behavior. Lethality has been found to be 4.78 times higher in males than in females. ${ }^{9}$ Men more often used

\footnotetext{
${ }^{*}$ Corresponding author.

E-mail address: halehghaem.epid@gmail.com (H. Ghaem).
} 
Table 1

Demographic characteristics and factors related to suicide among suicide attempters and fatal suicides in Najafabad during $2012-2016$.

\begin{tabular}{|c|c|c|c|c|c|}
\hline \multirow[t]{2}{*}{ Variables } & & \multicolumn{2}{|l|}{ Suicide } & \multirow[t]{2}{*}{ Total } & \multirow[t]{2}{*}{$P$ value } \\
\hline & & Fatal N (\%) & Nonfatal N (\%) & & \\
\hline \multirow[t]{5}{*}{ Age } & $<15$ & $5(0.2)$ & $122(5.7)$ & $127(5.9)$ & 0.04 \\
\hline & $15-24$ & $26(1.2)$ & $876(41)$ & $902(42.2)$ & \\
\hline & $25-34$ & $35(1.6)$ & $721(33.7)$ & $756(35.4)$ & \\
\hline & $35-44$ & $10(0.5)$ & $210(9.8)$ & $220(10.3)$ & \\
\hline & $>45$ & $11(0.5)$ & $122(5.7)$ & $133(6.2)$ & \\
\hline \multirow[t]{2}{*}{ Gender } & Male & $63(2.9)$ & $690(32.3)$ & $753(35.2)$ & $<0.001$ \\
\hline & Female & $24(1.1)$ & $1361(63.7)$ & 1385 (64.8) & \\
\hline \multirow[t]{5}{*}{ Education } & Uneducated & $3(0.1)$ & 293 (13.7) & $296(13.8)$ & 0.001 \\
\hline & Elementary & $4(0.2)$ & $238(11.1)$ & $242(11.3)$ & \\
\hline & Middle School & $23(1.1)$ & 417 (19.5) & $440(20.6)$ & \\
\hline & High School & $53(2.5)$ & $905(42.3)$ & $958(44.8)$ & \\
\hline & Diploma and university & $4(0.2)$ & $198(9.3)$ & $202(9.5)$ & \\
\hline \multirow[t]{2}{*}{ Marital status } & Single & 40 (1.9) & $945(44.2)$ & $985(46.1)$ & 0.986 \\
\hline & Married & $47(2.2)$ & $1106(51.7)$ & 1153 (53.9) & \\
\hline \multirow[t]{2}{*}{ History of Suicide } & Yes & $5(0.2)$ & $100(4.7)$ & $105(4.9)$ & 0.713 \\
\hline & No & $82(3.8)$ & 1951 (91.3) & $2033(95.1)$ & \\
\hline \multirow[t]{2}{*}{ Comorbidity } & Yes & $2(0.1)$ & $50(2.3)$ & $52(2.4)$ & 0.934 \\
\hline & No & $85(4)$ & 2001 (93.6) & $2086(97.6)$ & \\
\hline \multirow[t]{6}{*}{ Suicide method } & Medications & $33(1.5)$ & 1915 (89.6) & 1948 (91.1) & $<0.001$ \\
\hline & Hanging & $36(1.7)$ & $8(0.4)$ & $44(2.1)$ & \\
\hline & Cold Weapon & $6(0.3)$ & $23(1.1)$ & $29(1.4)$ & \\
\hline & Poisons & $5(0.2)$ & $75(3.5)$ & $80(3.7)$ & \\
\hline & Firearms & $5(0.2)$ & $2(0.1)$ & $7(0.3)$ & \\
\hline & Unknown & $2(0.1)$ & $28(1.3)$ & $30(1.4)$ & \\
\hline \multirow[t]{3}{*}{ Place of Residence } & Urban & $46(2.2)$ & $1244(58.2)$ & $1290(60.3)$ & 0.320 \\
\hline & Rural & $8(0.4)$ & $139(6.5)$ & $147(6.9)$ & \\
\hline & Urban side & $33(1.5)$ & $668(31.2)$ & $701(32.7)$ & \\
\hline
\end{tabular}

highly lethal methods in suicidal behavior, but there was also a higher method-specific lethality which together explained the large gender differences in the lethality of suicidal acts. ${ }^{10}$

Especially during the last decade the trend has been ascending. A study conducted in the west of the Iran revealed that women, low education and use of physical metals were regarded as the main risk factors for fatal suicides. Suicide rate is directly affected by the factor sex. ${ }^{11}$ Islamic Republic of Iran has the lowest suicide attempt rate compared to western countries but the greatest among the Middle East countries. $^{12}$

Suicide attempt is a costly event for our health care system and not congruent with our country's cultural and value criteria. During the last years suicide rate has revealed an increasing trend in Iran which affects both the subjects and their families negatively. Planners' and health care services developers' awareness of the rate is so beneficial in programming and extending such services. The present study aims to examine some epidemiological factors affecting attempted and completed suicide rate during 2012-2016 in NajafAbad, a city in Isfahan province.

\section{Materials and methods}

This is a cross-sectional study in NajafAbad, Isfahan province. NajafAbad is the 4th populated city in Isfahan and is located at its center. This city is at $27 \mathrm{~km}$ west of Isfahan including two main parts called Mehrdasht and Central.

The present study subjects are 2138 cases involved in suicide attempt during 2012-2016 that gone to Montazeri and Al-Zahra hospital. Those subjects who had been accidentally poisoned including food poisoning, poisoning through organophosphate materials and those with incomplete medical records were omitted from the study. The instrument adopted for gathering data were information registration forms which were filled by a trained to triage nurse in the emergency part of the hospital. Other necessary information were also extracted from the patients' medical records.

Demographic data were gathered from NajafAbad's registration office and health center to estimate completed and attempted suicide rate there. In the present study various variables including age, sex, region, marital status, education level, occupation status, history of suicide, suicide instruments, and outcome were examined. For better use of method of suicide in data analysis, two category of suicide (Physical versus chemical) created. Chemical used methods including medications or poisons compared to physical methods such as hanging, cutting and firearms.

\subsection{Statistical analysis}

Descriptive and analytical results including number, percent, mean, standard deviation, chi-square and bivariate and multivariate logistic regression were used. The backward logistic regression method was used. The Cochran-Armitage test trend analysis was used to examine attempted and completed suicide rate trend. $P$-value less than 0.05 was chosen as the significant condition in statistical relations. All the statistical analyses were conducted through software SPSS version 16 and Graphpad prism version 6.

\subsection{Ethical issues}

Prior to conducting the study, ethics committee confirmation were taken from Shiraz University of Medical Sciences (ethical code: 645742). Confidentiality of their personal data was emphasized.

\section{Result}

This study included 2138 cases of suicide during 2012-2016 among which 2051 (95.9\%) people attempted suicide and 87 (4.1\%) cases were fatal suicides. Totally, $1385(64.8 \%)$ patients were female and $4.9 \%$ of all cases had a history of suicide attempt, $53.9 \%$ of all cases were married and $47.8 \%$ were younger than 24 years of age. In our study, $90.6 \%$ of patients had lower than diploma or higher education and $2.4 \%$ of all cases have other disease with suicide.

The most common method of suicide was medication overdose (91.1\%) followed by use of poisons (3.5\%), hanging $(2.1 \%)$, cold 
Table 2

Methods of suicide (attempted and completed) by Gender, age, marital status, education and History of Suicide.

\begin{tabular}{|c|c|c|c|c|c|c|c|c|c|c|c|c|c|c|c|c|}
\hline \multirow[t]{3}{*}{ Variable } & & \multicolumn{15}{|c|}{ Method of suicide } \\
\hline & & \multicolumn{2}{|c|}{ Medications } & \multicolumn{2}{|c|}{ Hanging } & \multicolumn{2}{|c|}{ cutting } & \multicolumn{2}{|c|}{ Poisons } & \multicolumn{2}{|c|}{ Firearms } & \multicolumn{2}{|c|}{ Unknown } & \multicolumn{2}{|l|}{ Total } & \multirow[t]{2}{*}{$P$ value } \\
\hline & & $\mathrm{N}$ & $\%$ & $\mathrm{~N}$ & $\%$ & $\mathrm{~N}$ & $\%$ & $\mathrm{~N}$ & $\%$ & $\mathrm{~N}$ & $\%$ & $\mathrm{~N}$ & $\%$ & $\mathrm{~N}$ & $\%$ & \\
\hline \multirow[t]{2}{*}{ Gender } & Male & 654 & 30.6 & 38 & 1.8 & 18 & 0.8 & 28 & 1.3 & 5 & 0.2 & 10 & 0.5 & 753 & 35.2 & $<0.001$ \\
\hline & Female & 1294 & 60.5 & 6 & 0.3 & 11 & 0.5 & 52 & 2.4 & 2 & 0.1 & 20 & 0.9 & 1385 & $<0.001$ & \\
\hline \multirow[t]{2}{*}{ Age } & $<24$ years & 949 & 44.4 & 16 & 0.7 & 11 & 0.5 & 31 & 1.4 & 3 & 0.1 & 13 & 0.6 & 1023 & 47.8 & 0.219 \\
\hline & $>24$ years & 999 & 46.7 & 28 & 1.3 & 18 & 0.8 & 49 & 2.3 & 4 & 0.2 & 17 & 0.8 & 1115 & 52.2 & \\
\hline \multirow[t]{2}{*}{ Marital status } & Single & 900 & 42.1 & 19 & 0.9 & 12 & 0.6 & 34 & 1.6 & 4 & 0.2 & 16 & 0.7 & 985 & 46.1 & 0.875 \\
\hline & Married & 1048 & 49 & 25 & 1.2 & 17 & 0.8 & 46 & 2.2 & 3 & 0.1 & 14 & 0.7 & 1153 & 53.9 & \\
\hline \multirow[t]{2}{*}{ Education } & $<9$ years & 1757 & 82.2 & 43 & 2 & 28 & 1.3 & 77 & 3.6 & 7 & 0.3 & 24 & 1.1 & 1936 & 90.6 & 0.037 \\
\hline & $>9$ years & 191 & 8.9 & 1 & 0.0 & 1 & 0.0 & 3 & 0.1 & 0 & 0.0 & 6 & 0.3 & 202 & 9.4 & \\
\hline \multirow[t]{2}{*}{ History of Suicide } & Yes & 94 & 4.4 & 2 & 0.1 & 5 & 0.2 & 4 & 0.2 & 0 & 0 & 0 & 0 & 105 & 4.9 & 0.044 \\
\hline & No & 1854 & 86.7 & 42 & 2 & 24 & 1.1 & 76 & 3.6 & 7 & 0.3 & 30 & 1.4 & 2033 & 95.1 & \\
\hline
\end{tabular}

weapon (1.2\%), Firearms (0.7\%) and (1.4\%) were unknown. Considering the kind of suicide, demographic, psychological and socioeconomic characteristics of patients are shown in Table 1.

Table 2 shows the methods of suicide (attempted and completed) by gender, age, marital status, education and history of suicide. Medications and poisons was a more frequent method used in females than males $(60.5 \%$ versus $30.6 \%$ and $2.4 \%$ versus $1.3 \%$ respectively). Whereas hanging and cutting were used by more men than women ( $1.8 \%$ versus $0.3 \%$ and $0.8 \%$ versus $0.5 \%$ respectively).

Analysis of methods based on marital status showed that medications was more prevalent among the married (49\%) than the singles $(42.1 \%)$. Hanging $(1.2 \%)$, cutting (0.8) and use of poisons $(2.1 \%)$ was more frequent in married than the singles.

Subjects that have lower than 9 years of education more frequent use of medications $(82.2 \%)$. Subject that no experience of suicide more frequent use of medication than subject have history of suicide $(86.7 \%$ versus $4.4 \%$ respectively). Statistically no difference between method of suicide and age of subjects.

Logistic models in Tables 3 and 4 are presented as unadjusted and adjusted models for calculate the odds ratio (OR) and 95\% confidence interval (CI) for people with fatal suicide compared with non-fatal. Unadjusted logistic regression model showed that variables of gender (male vs. female) with (OR: 5.17, $P<0.001$ ), education level (<9years vs. $>$ 9years) with (OR: $2.21, p=0.124$ ) and history of Suicide (yes vs. no) with (OR: $1.19, p=0.713$ ) increased the odds of fatal suicide. Also, variables of Age $(<24$ years vs. $>24$ years $)$ with (OR: $0.59, P=0.021$ ), marital status (single vs. married) with (OR: $0.99, \mathrm{p}=0.986$ ) and Suicide method (physical vs. chemical) with (OR: $0.013, P<0.001$ ), reduced the chance of suicide.

In multivariable analysis, male gender (OR: 2.67; CI 95\% 1.53 to 4.64) was a risk factor for fatal suicide and application of chemical methods (OR: 0.018; CI 95\% 0.010 to 0.032 ) was a protective factor.

Results regarding completed suicide trend analysis shows that this trend has had a significant statistical difference in men, so that in 2015 this figure has achieved its highest level but in women this trend doesn't manifest such a significant difference $(p=0.209)$. Results regarding attempted suicide trend rate has not shown a significant statistical difference for both males and females $(p=0.131$ for men and
Table 4

Adjusted Odds ratio (OR) and 95\% confidence interval (95\% CI) of fatal suicide based on binary logistic regression model.

\begin{tabular}{llll}
\hline Variable & \multicolumn{2}{l}{ Adjusted Odds ratio (OR) } \\
\cline { 2 - 4 } & $\begin{array}{l}\text { Odds ratio } \\
\text { (OR) }\end{array}$ & $\begin{array}{l}\text { 95\% confidence } \\
\text { interval }\end{array}$ & P value \\
\hline $\begin{array}{l}\text { Gender (male vs. female) } \\
\begin{array}{l}\text { Suicide method (physical vs. } \\
\text { chemical) }\end{array}\end{array}$ & $\begin{array}{l}2.67 \\
(1.53-4.64)\end{array}$ & $\begin{array}{c}0.001 \\
<0.001 \\
(0.010-0.032)\end{array}$ \\
\hline
\end{tabular}

Table 5

Trend analysis of suicide attempt and fatal suicide (per 100,000) in Najafabad (2012-2016).

\begin{tabular}{lllllll}
\hline \multicolumn{2}{l}{ luicide attempt } \\
\hline Year & 2012 & 2013 & 2014 & 2015 & 2016 & $P$ value \\
Male & 93 & 123.9 & 74.8 & 65.7 & 105.1 & 0.131 \\
Female & 169.7 & 230.3 & 156.2 & 130 & 209 & 0.504 \\
Total & 130.2 & 175.5 & 114.4 & 97.1 & 156.5 & 0.170 \\
Fatal suicide & & & & & & \\
Year & 2012 & 2013 & 2014 & 2015 & 2016 & $P$ value \\
Male & 3.79 & 7.40 & 5.39 & 12.32 & 9.38 & 0.019 \\
Female & 5.36 & 1.31 & 5.08 & 1.23 & 2.58 & 0.209 \\
Total & 4.56 & 4.45 & 5.24 & 6.91 & 6.04 & 0.188 \\
\hline
\end{tabular}

$p=0.504$ for women). Trend analysis of the rate of suicide attempt and fatal suicide in Najafabad is presented in table 5 and Fig. 1.

\section{Discussion}

According to the results of our study, about half of the suicide attempt cases has occurred among age groups lower than 24 . Also the highest suicide attempt rate was for women $(64.8 \%)$ and the married people (53.9\%). The most common reported suicide method was found to be drug overdose $91.1 \%$. In one study done in Ilam by the Nazarzadeh et al., the same findings were gained. ${ }^{11}$ Also in a retrospective study in Iran the most common methods of suicide way

Table 3

Unadjusted Odds ratio (OR) and 95\% confidence interval (95\% CI) of fatal suicide based on binary logistic regression model.

\begin{tabular}{|c|c|c|c|}
\hline Variables & Odds ratio (OR) & $95 \%$ confidence interval & $\mathrm{P}$ value \\
\hline Gender (male vs. female) & 5.17 & $(3.20-8.35)$ & $<0.001$ \\
\hline Age $(<24$ years vs. $>24$ years $)$ & 0.59 & $(0.37-0.92)$ & 0.021 \\
\hline Education (< 9years vs. > 9years) & 2.21 & $(0.8-6.1)$ & 0.124 \\
\hline Suicide method (physical vs. chemical) & 0.013 & $(0.008-0.023)$ & $<0.001$ \\
\hline Marital status (single vs. married) & 0.99 & $(0.64-1.53)$ & 0.986 \\
\hline History of Suicide (yes vs. no) & 1.19 & $(0.47-3.0)$ & 0.713 \\
\hline
\end{tabular}



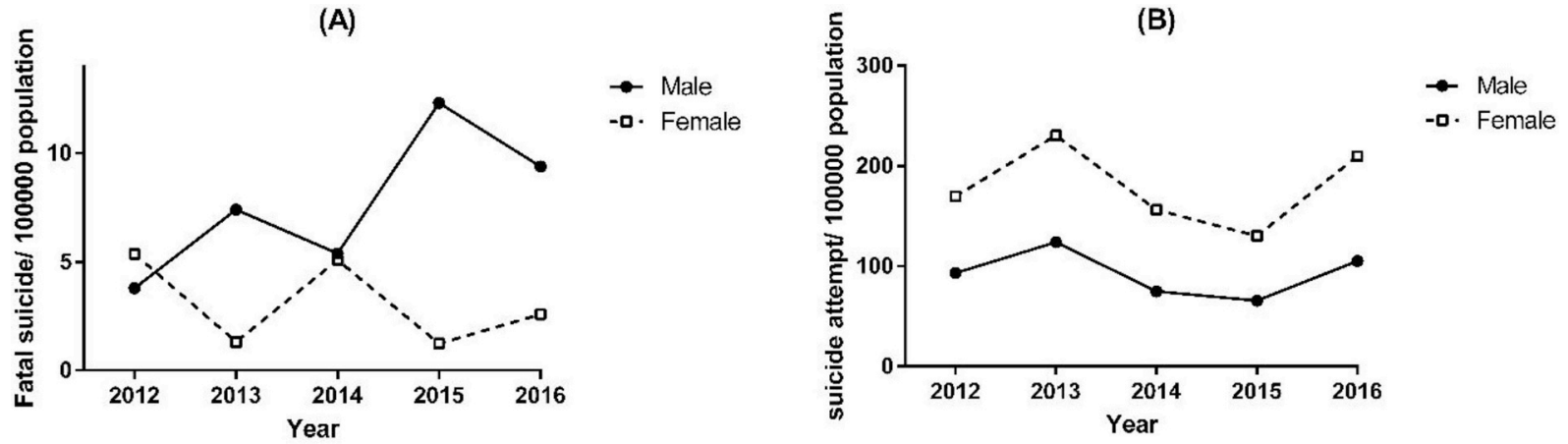

Fig. 1. Trend of suicide in Najafabad from 2012 to 2016; (A) Fatal suicide; (B) Suicide attempt.

reported drug overdose or use of poisons. ${ }^{11,13}$ Puzo et al. show that the most frequently used suicide method in the total population of Norway was hanging. ${ }^{14}$ In review study about suicide methods in Asian countries, hanging was the most common suicide method in nine out of the seventeen countries/regions reviewed. ${ }^{15}$

In the present study other influential factors on suicide attempt methods were examined. Studies have shown significant variations in methods among men and women. ${ }^{13,16}$ Women use milder methods including drug overdose, while hanging was a more frequent aggressive method used in men. ${ }^{17,18}$ Our findings were also congruent with other studies done in other areas of Islamic Republic of Iran. ${ }^{19,20}$ On the other hand those subjects having a history of suicide used milder methods compared to those who didn't. The main reason for this can be the perceived suffering and harm by subjects having a history of suicide. ${ }^{21}$ In the study about Suicide methods in Europe, hanging was the most prevalent suicide method among both males (54.3\%) and females $(35.6 \%){ }^{22}$

Multivariate regression analysis showed that age, educational level, marital status, and having history of suicide were among the risk factors for fatal suicide in men. Chemical used methods including drugs or poisons compared to physical methods such as hanging and use of weapons were recognized as protected variables. On the other hand in a similar study conducted in Ilam, variables including females, physical method and age lower than 24 were recognized as the risk factors on the suicide outcome. ${ }^{23}$ Findings of the present study confirmed that completed suicide attempt has had an increasing trend for men in NajAfabad which was also statistically significant, while this trend has not been significant for women. Lau et al. found that older age was related to an elevated risk for suicidal presentation among youth. ${ }^{24}$ Wong and Maffini found that stronger school relationships were associated with higher rates of suicide attempts among adolescents. ${ }^{25}$ Nilamadhab Kar in his study in India revealed that compared to the controls, significantly more number of attempters had a family history of psychiatric illness and suicide, childhood trauma, medical consultation within one month, had experienced stressful life events and had expressed suicidal ideas. ${ }^{26}$ Many researchers have attempted to find explanations for why gender is such a significant indicator for suicide. A common explanation relies on the social constructions of hegemonic masculinity and femininity. According to literature on gender and suicide, male suicide rates are explained in terms of traditional gender roles. Male gender roles tend to emphasize greater levels of strength, independence, risk-taking behavior, economic status, individualism ${ }^{27,28}$

The highest completed suicide rate figure for men was 12.32 per 100000 in 2015. For women this value of 5.36 per 100000 in 2012. According to the studies done in Iran, the highest completed suicide was reported in the west of Iran especially Ilam and Lorestan provinces. This is while the lowest rate was reported in northwest of Iran such as Zanjan and Eastern Azarbaijan., ${ }^{5,6}$ This difference might be due to ethnic varieties, religious beliefs, economic-social levels, atmospheric conditions and region temperature, having access to methods of suicide in people living in different areas. ${ }^{29-31}$

According to the results of our study the attempted suicide rate in women was higher than men but the results of more analysis revealed no significant statistical difference. The highest suicide rate was in men, 123.9 per 100000 in 2013 . For women the highest rate was 230.3 per 100000 in 2013. Our findings were congruent with other research done in central areas of Iran including Isfahan, Semnan, Yazd and Qom which have revealed the greatest suicide attempt rate. ${ }^{32-34}$ Based upon a meta-analysis study in Iran, the value was 114 per 100000 in central cities whereas in western regions the figures have shown the lowest suicide attempt rate, 36 per 100000 , but the highest completed suicide rate. $^{5}$ Mościcki mentioned that attempted suicides occur primarily among women, while completed suicides occur primarily among men. ${ }^{35}$ Freeman et al. in his study show that a significant association between suicide intent and gender was found, where 'Serious Suicide Attempts' (SSA) were rated significantly more frequently in males than females. ${ }^{36}$ This difference might be due to demographic characteristics, climate and personality traits of people living in these areas whose completed suicide rate is so high.

\subsection{Strengths and limitations of the study}

One of the strengths of the present study is examining suicide trend during 2012-2016. One of the limitations of the present study can be lack of information by age in order to calculate standardized attempted and completed suicide rate in this region. On the other hand, under reporting is a serious issue in health related problems dealing with a stigmatized condition such as suicide.

\section{Conclusion}

According to the findings of the present study, attempted and completed suicide rate is relatively high in Najafabad compared to other regions in Islamic Republic of Iran. It could suggest the socioeconomic situation of people, gender difference and method of suicide attempt at the national level is a sensitive issue. It is also suggested researcher focused on the prevention of suicide.

\section{Details of funding source}

My Research Project was fully sponsored by $\{$ Shiraz University of Medical Sciences\} with grant number \{96-01-42-15740\}

\section{Conflicts of interest}

No declare.

\section{Acknowledgement}

The present study was financially supported by Shiraz University of 
Medical Sciences, Shiraz, Iran (Grant number: 96-01-42-15740) and collaboration with Isfahan University of Medical Sciences, Isfahan, Iran

\section{Appendix A. Supplementary data}

Supplementary data to this article can be found online at https:// doi.org/10.1016/j.cegh.2018.12.009.

\section{References}

1. Dua T, Barbui C, Clark N, et al. Evidence-based guidelines for mental, neurological, and substance use disorders in low- and middle-income countries: summary of WHO recommendations. PLoS Med. 2011;8(11):e1001122.

2. Värnik P. Suicide in the world. Int J Environ Res Publ Health. 2012;9(3):760-771.

3. Rezaeian M. Epidemiological characteristics of suicide cases in Rafsanjan from 2004 to 2009: the roles of family disputes and unemployment. J Occup Health Epidemiol. 2012;1(2):75-80.

4. Rostami C, Karami K, Daliri S, Mardani A, Narimisa F. Epidemiological study of suicide in Khuzestan province, south west of Iran, during 2011 to 2014. Archiwum Medycyny Sadowej i Kryminologii/Arch Forensic Med Criminol. 2017;67(1):46-60.

5. Daliri S, Bazyar J, Sayehmiri K, Delpisheh A, Sayehmiri F. The incidence rates of suicide attempts and successful suicides in seven climatic conditions in Iran from 2001 to 2014: a systematic review and meta-analysis. Sci J Kurdistan Univ Med Sci. 2017;21(6).

6. Rostami C, Daliri S, Sayehmiri K, Delpisheh A, Sayehmiri F. The incidence of suicide attempt in Iran (2001-12) \&58; A meta-analysis. J Kerman Univ Med Sci 2016;19(7):374-382.

7. Turecki G, Brent DA. Suicide and suicidal behaviour. Lancet (London, England). 2016;387(10024):1227-1239.

8. Vijayakumar L. Suicide in women. Indian J Psychiatr. 2015;57(Suppl 2):S233-S238.

9. Mergl R, Koburger N, Heinrichs K, et al. What are reasons for the large gender differences in the lethality of suicidal acts? An epidemiological analysis in four european countries. PLoS One. 2015;10(7):e0129062-e.

10. Tsirigotis K, Gruszczynski W, Tsirigotis M. Gender differentiation in methods of suicide attempts. Med Sci Mon Int Med J Exp Clin Res : Int Med J Exp Clin Res. 2011;17(8):PH65-PH70.

11. Nazarzadeh M, Bidel Z, Ranjbaran M, et al. Fatal suicide and modelling its risk factors in a prevalent area of Iran. Arch Iran Med. 2016;19(8):571-576.

12. Ghoreishi SA, Mousavinasab N. Systematic review of researches on suicide and suicide attempt in Iran. Iran J Clin Psychol. 2008;14(2):115-121.

13. Hakim Shooshtari M, Malakouti SK, Panaghi L, Mohseni S, Mansouri N, Rahimi Movaghar A. Factors associated with suicidal attempts in Iran: a systematic review. Iran J Psychiatr Behav Sci. 2016;10(1):e948

14. Puzo Q, Qin P, Mehlum L. Long-term trends of suicide by choice of method in Norway: a joinpoint regression analysis of data from 1969 to 2012. BMC Public Health. 2016;16:255.

15. Wu KC-C, Chen Y-Y, Yip PSF. Suicide methods in asia: implications in suicide prevention. Int J Environ Res Publ Health. 2012;9(4):1135-1158.

16. Lewinsohn PM, Rohde P, Seeley JR, Baldwin CL. Gender differences in suicide attempts from adolescence to young adulthood. J Am Acad Child Adolesc Psychiatr. 2001;40(4):427-434

17. Wichstrøm L, Hegna K. Sexual orientation and suicide attempt: a longitudinal study of the general Norwegian adolescent population. J Abnorm Psychol. 2003;112(1):144.

18. Hoertel N, Franco S, Wall M, et al. Mental disorders and risk of suicide attempt: a national prospective study. Mol Psychiatr. 2015;20(6):718.

19. Amiri MM, Livani AA, Moosazadeh M, Mirzajani M, Dehghan A. Seasonal pattern in suicide in Iran. Iran J Psychiatr Behav Sci. 2015;9(3).

20. Pajoumand A, Talaie H, Mahdavinejad A, et al. Suicide epidemiology and characteristics among young Iranians at Poison Ward, Loghman-Hakim hospital (19972007). Arch Iran Med. 2012;15(4):210-213.

21. McDermott E, Roen K. Queer Youth, Suicide and Self-harm: Troubled Subjects, Troubling Norms. Springer; 2016.

22. Värnik A, Kõlves K, van der Feltz-Cornelis CM, et al. Suicide methods in Europe: a gender-specific analysis of countries participating in the "European Alliance against Depression". J Epidemiol Community Health. 2008;62(6):545-551.

23. Nazarzadeh M, Bidel Z, Ranjbaran M, et al. Fatal Suicide and Modelling its Risk Factors in a Prevalent Area of Iran. 2016; 2016.

24. Lau AS, Jernewall NM, Zane N, Myers HF. Correlates of suicidal behaviors among Asian American outpatient youths. Cult Divers Ethn Minor Psychol. 2002;8(3):199-213.

25. Wong YJ, Maffini CS. Predictors of Asian American adolescents' suicide attempts: a latent class regression analysis. J Youth Adolesc. 2011;40(11):1453-1464

26. Kar N. Profile of risk factors associated with suicide attempts: a study from Orissa, India. Indian J Psychiatr. 2010;52(1):48-56.

27. Payne S, Swami V, Stanistreet DL. The social construction of gender and its influence on suicide: a review of the literature. J Men's Health. 2008;5(1):23-35.

28. Webster Rudmin F, Ferrada-Noli M, Skolbekken JA. Questions of culture, age and gender in the epidemiology of suicide. Scand J Psychol. 2003;44(4):373-381.

29. Becker SO, Woessmann L. Social Cohesion, Religious Beliefs, and the Effect of Protestantism on Suicide. Review of Economics and Statistics. 2015; 2015 (0).

30. Kim Y, Kim H, Honda Y, et al. Suicide and ambient temperature in East Asian countries: a time-stratified case-crossover analysis. Environ Health Perspect. 2016;124(1):75.

31. Betz ME, Miller M, Barber C, et al. Lethal means access and assessment among suicidal emergency department patients. Depress Anxiety. 2016;33(6):502-511.

32. Khorshidi A, Sayehmiri K, Babanejad M. Seasonality of suicide occurrence in Ilam. Iran J Epidemiol. 2014;9(3):17-23.

33. Taziki M, Semnani S, Golalipour M, et al. Epidemiological survey of suicide in Golestan province in the North of Iran (2003). J Mazandaran Univ Med Sci. 2006;16(55):72-77.

34. Janghorbani M, Bakhshi S. The prevalence of suicide ideation and factors associated among students of Isfahan University of Medical Sciences, 2013-2014. J Shahrekord Univ Med Sci. 2015;17.

35. Moscicki EK. Gender differences in completed and attempted suicides. Ann Epidemiol 1994;4(2):152-158.

36. Freeman A, Mergl R, Kohls E, et al. A cross-national study on gender differences in suicide intent. BMC Psychiatry. 2017;17:234. 